\title{
Application of Information Technology Tools in Teaching the Course and Laboratory of Power Electronics
}

\author{
Shuhui Li and Rajab Challoo \\ Department of Electrical Engineering \& Computer Science \\ Texas A\&M University - Kingsville \\ Kingsville, TX 78363
}

\begin{abstract}
This paper presents the application of information technology (IT) tools in teaching the course of Power Electronics at Texas A\&M University - Kingsville (TAMUK). It illustrates the usage of the power-pole and average models in the teaching so as to be able to introduce broad power electronic converter topologies. It shows the development of a new power electronics laboratory by using modern computer IT tools. It presents how PSpice simulation is used as a virtual hardware laboratory tool to teach different converter topologies and feedback control design and analysis. Mathcad is shown in the paper as another valuable IT tool for teaching the theoretical background and design issues related to power electronic converters and feedback controls. The paper illustrates the application of web-based course materials to assist students' understanding of basic operating principles and properties of power electronic converters. It gives PSpice, Mathcad, MATLAB Simulink, dSPACE ControlDesk, OpenChoice and Microsoft Excel software and/or hardware used in both the teaching and laboratory development for the course.
\end{abstract}

\section{INTRODUCTION}

In recent years, the field of power electronics has witnessed extraordinary research and teaching growth worldwide, emerging as a specialization in electrical engineering. This growth is due to expanding market demand for power electronic circuits for the energy conversion process. The need for power electronics engineers equipped with knowledge of new energy conversion technologies has never been greater. However, because of the breath of the field of power electronics, teaching this subject to undergraduate students is a challenge.

As it is known, computers and microprocessors have changed the field of traditional electrical engineering a lot. They are also changing the traditional teaching styles in high education. When digital computers or microprocessors as well as various software and hardware are used in classrooms and/or laboratories, it can provide a much more effective and efficient way in teaching and learning, and make a lot of mathematics related to engineering problems much easier to understand. This is also true for teaching the course of Power Electronics. 
The electrical engineering program at TAMUK offers Power Electronics as an elective course. In order to continuously improve the course and attract more students to the field, various computer software and hardware IT tools have been introduced to restructure both the lecture and laboratory parts of the course. This paper presents our teaching practice in power electronics. Section II gives comparison between hardware measurement and software simulation for the purpose of developing students an understanding of virtual laboratory through simulation. Section III illustrates the use of PSpice simulation tool for teaching different converter topologies. Section IV demonstrates how MathCad is used as a powerful mathematical tool for theoretical analysis and design. Section V introduces teaching approaches for feedback control design of DC/DC converters. Section VI illustrates a web-based seminar used to assist students' understanding of basic principles and concepts in power electronics. Section VII gives the newly developed Power Electronics Laboratory at TAMUK with the introduction of various modern computer IT tools. Finally, it gives the conclusions.

\section{COMPARISON BETWEEN MEASUREMENT AND SIMULATION USING LABVIEW AND PSPICE}

There are many circuit simulation tools that can simulate electric and electronic circuits and also have functionalities to perform circuit analyses for simulation data. PSpice and Electronics Workbench are two typical circuit simulation tools among them [1 - 3]. Although it is significant to incorporate measurements with theoretical calculations for quality education, the valuable role of simulation cannot be ignored [4]. First, the circuit simulation can provide a strong virtual laboratory environment for a practical experiment. Second, it is much faster to build or modify an electric circuit or system in simulation than in hardware. Third, with rich circuit analysis functionalities in most circuit simulation IT tools, analysis and design of an electric/electronic circuit is very easy to perform in software simulation environment $[5,6]$.

However, it is critical to let students see the relation and comparison between hardware measurement and software simulation in order for them to gain better understanding and stronger confidence on using simulation IT tools for various power electronic circuit analysis and designs. At TAMUK, there is a course of Circuits and Electronics Lab, which has fourteen experiments related to measurement and simulation of typical electric and electronic circuits, filters and Bode plots, operational amplifiers, and analog to digital and digital to analog conversions. Students take this course before the course of Power Electronics. In the newly restructured course of Circuits and Electronics Lab [7], we have introduced National Instruments LabView software and DAQ hardware and various other computer IT tools, making it practical and possible to compare computer measurement and PSpice simulation in many different ways. Students are required to do hardware measurements using LabView, simulation using PSPice, theoretical calculation using Mathcad, and result comparison among results gained from all the three approaches for most experiments.

Figure 1 presents an example of using computer data acquisition hardware and a LabView program to measure the transients of a series RC circuit under a square wave input voltage as well as corresponding comparison between hardware measurement and software simulation. After the measuring circuit is set up and is provided with necessary connections to DAQ analog input channels, measuring results can be displayed in the front panel of the program 
by clicking the running icon. Any result in the front panel can be screen captured as shown in Figure $1 \mathrm{a}$ ) or saved to a file by clicking the Save button. Large amount of data saved in the file can then be loaded into a spreadsheet table and compared with simulation results generated by other IT tools such as PSpice (Figure $1 \mathrm{~b}$ ). Similar comparison is given in Figure 2 for another example of measurement, simulation and theoretical calculation of Bode plots obtained through LabView, PSpice, and Mathcad for a RC highpass filter.

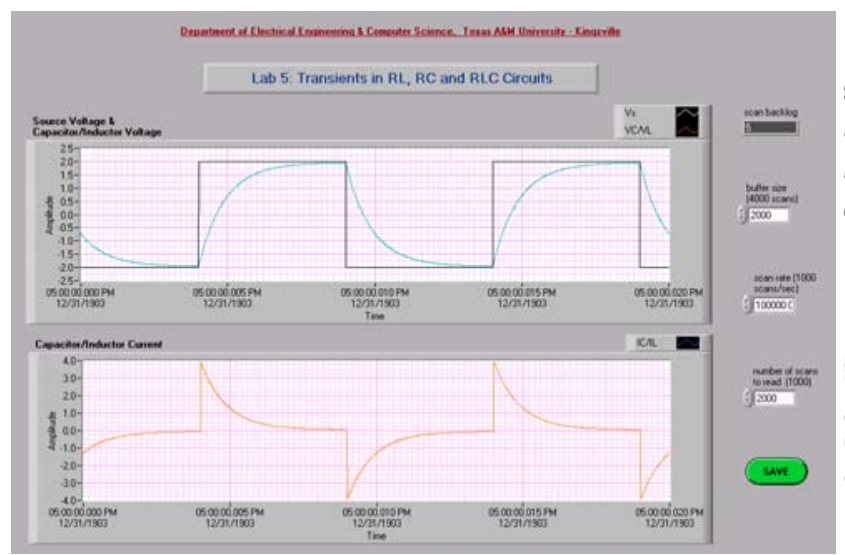

a) Measured results by screen capture

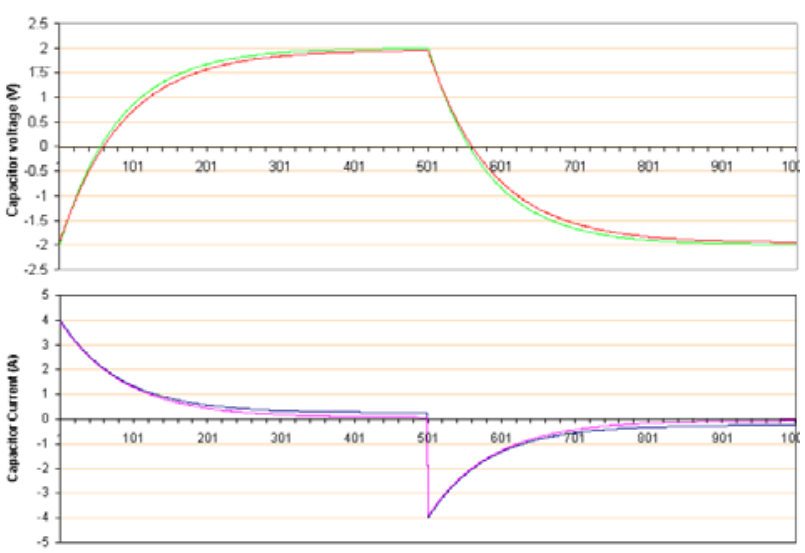

b) Comparison of measured/calculated results

Figure 1. Measured and calculated results for transient of a RC circuit

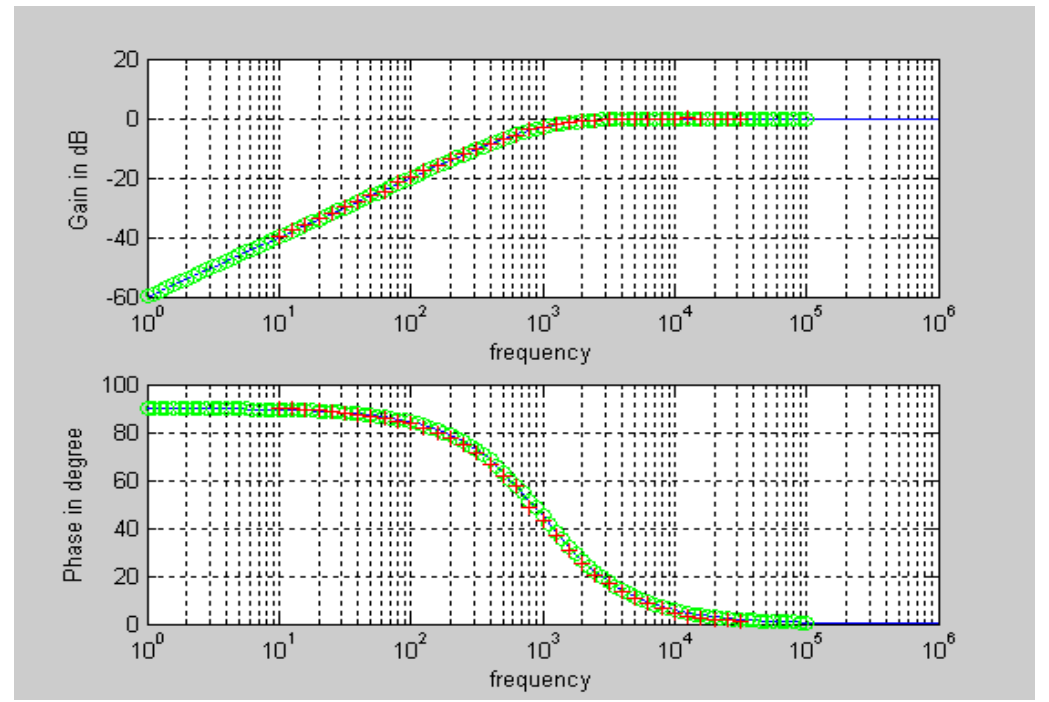

Figure 2. Result comparison among Mathcad calculation '-', Pspice simulation '-0-', and NI ELVIS measurement '-+-'

Extensive comparisons in various aspects from the 14 experiments have built a valuable foundation not only for many other courses but also for successful teaching of Power Electronics in our program. In other words, it gives students intense impression that PSpice simulation could accurately describe actual circuit performances when the simulation circuit is appropriately represented. This has given students strong confidence when using PSpice simulation for design and analysis of power electronic converters, drive circuits, and/or analog controller.

\section{TEACHING POWER ELECTRONICS WITH PSPICE SIMULATION TOOL}


PSpice is a member of SPICE "family" circuit simulators, all of which derive from the SPICE2 circuit simulator developed at the University of California, Berkeley [1, 2]. SPICE is a general-purpose circuit simulation program that simulates electric and electronic circuits and can perform various electric and electronic circuit analyses. Because of the enormous complexity of modern integrated circuits, computer-aided circuit analysis tools such as PSpice are essential and can provide information about circuit performance that is almost impossible or impractical to obtain with laboratory prototype measurements.

Before taking the course of Power Electronics, our students usually have had background in Electric Circuits, Electronics, and Circuits and Electronics Lab [7 - 8]. They have developed a proper PSpice simulation capability from those courses and gained good impression that the simulation can give results close to those of a practical circuit if the simulation circuit is properly represented (Figures 1, 2). This will give them good confidence to use PSpice simulation as a virtual laboratory, making the simulation a very practical hardware replacement for teaching power electronics in a classroom environment.

The PSpice simulation IT tool has been used as a strong virtual laboratory to teach many tough power electronic transients and switching phenomena. The student version PSpice package, which is free to download, can be used to simulate most power electronic circuits and systems. The simulation can not only emulate transient behaviors of various branch currents and node voltages of a converter but also provide flexible functionalities for calculation of a variety of electric characteristics for power electronic converter designs and analysis.

Figure 3 shows a PSpice schematics of a SCR controlled inverter [10]. On the one hand, the converter circuit diagram of Figure 3 a) gives students a good high-level graphic representation of the converter topology and the control from the drive circuit to the SCRs. On the other hand, the block of the drive circuit is linked to a subcircuit which provides the details or the principle of how the SCR control signals are generated. The simulation results of the inverter can be analyzed and presented in Probe (Figure 3 b) in a step-by-step approach to lead students from fundamental concepts to full understanding of the inverter operating principle most effectively and efficiently. For example, an instructor can first show the plot of the source voltage, then add a plot to illustrate the SCR output voltage, and then add another plot to show the SCR control signals, etc. The effect of this PSpice assisted teaching approach presents a strong virtual laboratory environment for students to most effectively understand the operations and theories of different power electronic converters.

The simulation IT tool is also used to assist students to design and analyze various power electronic converters. Although most design tasks of a power electronic converter are mainly carried out by using mathematical IT tools, the PSpice simulation is used as a virtual laboratory to check the correctness of the design and to re-emphasize students' understanding of theories in the virtual laboratory environment. For some situations when factors such as internal impedance in a source and/or in electric/electronic components are hard to be considered in a theoretical design, it is very easy, however, for students to modify the corresponding circuit schematic in PSpice, re-simulate the circuit, and then compare new simulated results with theoretically calculated results. In this way, not only can theories be more clarified but also the deviation of more practical results caused by such factors can be understood. 


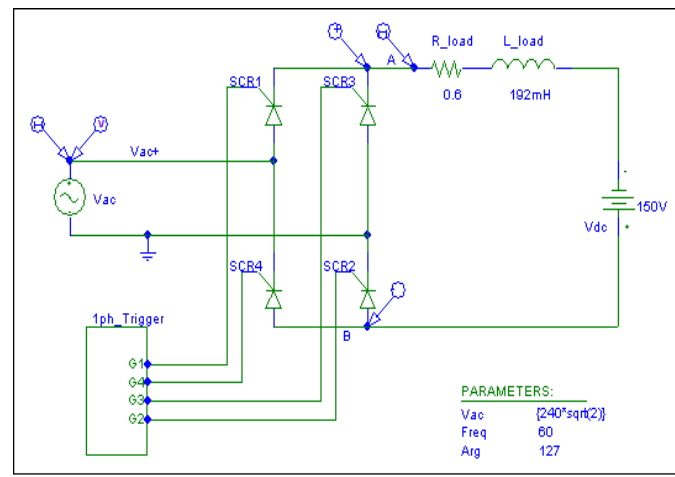

a) The inverter

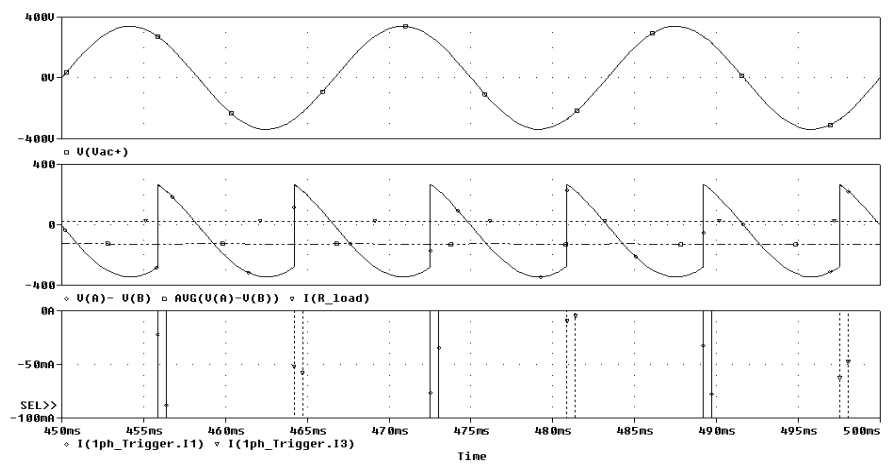

b) Simulation results

Figure 3. SCR controlled single phase converter as an inverter

\section{ANALYSIS AND DESIGN OF POWER ELECTRONIC CONVERTERS USING MATHCAD}

Mathcad is the industry standard calculation software for technical professionals, educators, and college students [11]. Mathcad is as versatile and powerful as programming languages, yet it's as easy to learn as a spreadsheet. One can place equations, text, and graphics anywhere in the Mathcad worksheet. The equations are live. That is, equations appear as one is used to seeing them on blackboards or in reference books, and as soon as one make a change anywhere in your worksheet, Mathcad updates results and redraws graphs. This makes it easy to keep track of the most complex calculations [12 - 15].

Because of these, Mathcad is used as another powerful computer IT tool for teaching the undergraduate Power Electronics at TAMUK. By using Mathcad, we have introduced students to many design practices and concepts through the course. The course has provided students excellent design opportunities and experiences especially from electric and electronic circuit and system control points of views. To design a converter under certain condition, a student first types equations and data of design specifications in Mathcad worksheet based on certain theoretical background, and then the Mathcad calculates the results and/or draw plots for the design automatically. If a design is unsatisfactory, a student can change design data and then results will be recalculated and/or redrawn automatically, making it convenient to manage designs of power electronic converters effectively and efficiently. The mathematical design results/plots can also be examined in PSpice simulation so as to let students more clearly understand the relation between theoretical calculations and virtually "measured" results and therefore re-emphasize their comprehension of theories.

Figure 4 shows an example of designing a DC/AC inverter using Mathcad. In a Mathcad worksheet, a student just needs to provide known data and design specifications, and type mathematical equations necessary for the design according to relevant theories. Then, the Mathcad automatically does all the calculations. All the results shown in Mathcad also come with units so that mistakes or inconsistencies of data and equations in the worksheet can be more easily and quickly identified. If a design is not satisfactory, it is very easy to modify data or design specifications, and then the Mathcad will recalculate automatically to get a new design. After the design, simulation (Figure 5) can be performed to let students more clearly observe 
virtual laboratory performance of the inverter versus the theoretical design so as to re-emphasize their understanding of theories. In the simulation, factors related to non-ideal electric and electronic components can be included to examine their effect to a theoretical design.

\section{Design of $\mathscr{D C}$ to $A C$ Comverter}

Design specifications:

$\mathrm{V}_{1 \mathrm{mms}}:=120 \cdot \mathrm{V} \quad \mathrm{R}:=14 \Omega \quad \mathrm{L}:=28 \cdot \mathrm{mH} \quad \mathrm{f}:=60 \cdot \mathrm{Hz} \quad \mathrm{THD}_{\mathrm{I}}:=8 \% \quad \omega_{0}:=2 \cdot \pi \cdot \mathrm{f}$

a) Select dc input voltage: $\quad V_{d c}:=200 \cdot v$

b) Calculate amplitude modulation ratio: $\quad \mathrm{m}_{\mathrm{a}}:=\frac{\mathrm{V}_{1 \mathrm{mms}} \sqrt{2}}{\mathrm{~V}_{\mathrm{dc}}} \quad \mathrm{m}_{\mathrm{q}}=0.849$

c) Decide total harmonic current:

- Choose bipolar PWM switching scheme

- Calculate fundamental current for the design: $\quad z_{1}:=R+j \cdot \omega_{0} \cdot L \quad I_{1 \mathrm{mms}}:=\frac{V_{1} \mathrm{mms}}{\left|z_{1}\right|} \quad I_{1 \mathrm{mms}}=6.844 \mathrm{~A}$

- Calculate total harmonic current according to the design specification THD requirement on rms values of the total harmonic current:

$$
\frac{\mathrm{I}_{\mathrm{mf}}}{\sqrt{2}}=\sqrt{\sum_{\mathrm{n}=2}^{\infty}\left(\mathrm{I}_{\mathrm{nms}}\right)^{2}}<\mathrm{THD}_{\mathrm{I}} \cdot \mathrm{I}_{1 \mathrm{~ms}} \quad \mathrm{I}_{\mathrm{mf}}:=\mathrm{THD}_{\mathrm{I}} \cdot \mathrm{I}_{1 \mathrm{~ms}} \cdot \sqrt{2} \quad \mathrm{I}_{\mathrm{mf}}=0.774 \mathrm{~A}
$$

d) Design/Compute switching frequency:

- Normalized Fourier coefficients $\vee \mathrm{n} N \mathrm{dc}$ :

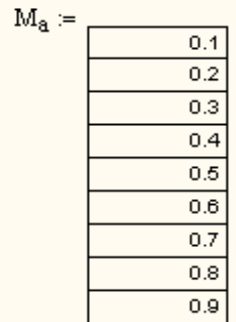

$\mathrm{M}_{\mathrm{f}}:=$

\begin{tabular}{|r|}
\hline $1.27 \cdot 10^{0}$ \\
\hline $1.24 \cdot 10^{0}$ \\
\hline $1.2 \cdot 10^{0}$ \\
\hline $1.15 \cdot 10^{0}$ \\
\hline $1.08 \cdot 10^{0}$ \\
\hline $1.01 \cdot 10^{0}$ \\
\hline $920 \cdot 10^{-3}$ \\
\hline $820 \cdot 10^{-3}$ \\
\hline $710 \cdot 10^{-3}$ \\
\hline
\end{tabular}

- Normalized Fourier coefficients for this design:

$\operatorname{Coff}_{\mathrm{f}}:=\operatorname{linterp}\left(\mathrm{M}_{\mathrm{a}}, \mathrm{M}_{\mathrm{f}}, \mathrm{m}_{\mathrm{a}}\right)$

$\operatorname{Coff}_{\mathrm{f}}=0.767$

- Frequency modulation ratio:

$$
\mathrm{V}_{\mathrm{mf}}:=\operatorname{Coff}_{\mathrm{f}} \cdot \mathrm{V}_{\mathrm{dc}} \quad Z_{\mathrm{mf}}:=\frac{\mathrm{V}_{\mathrm{mf}}}{\mathrm{I}_{\mathrm{mf}}} \quad \mathrm{m} f \mathrm{f}_{\mathrm{f}}:=\frac{Z_{\mathrm{mf}}}{\omega_{0} \cdot \mathrm{L}}
$$

- Switching frequency:

Select

$\mathrm{m}_{\mathrm{f}}:=20 \quad \mathrm{f}_{\mathrm{tri}}:=\mathrm{m}_{\mathrm{f}} \cdot \mathrm{f}$

$\mathrm{f}_{\mathrm{tri}}=1.2 \mathrm{KHz}$

Figure 4. Design of a DC/AC inverter using Mathcad

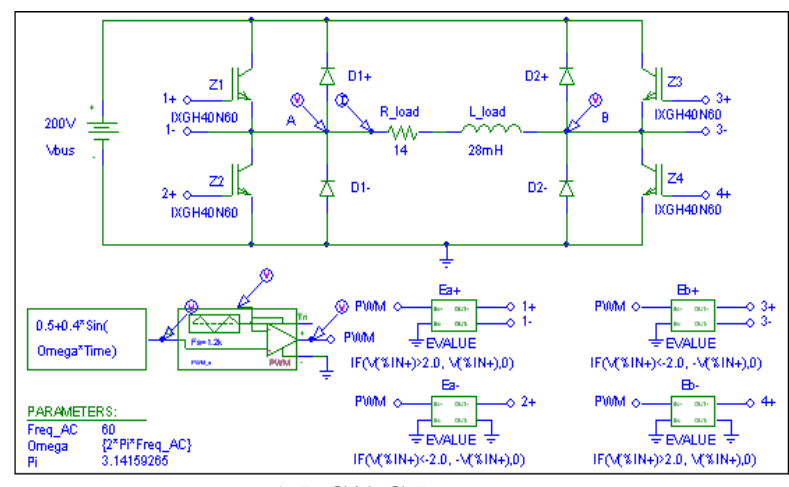

a) DC/AC Inverter

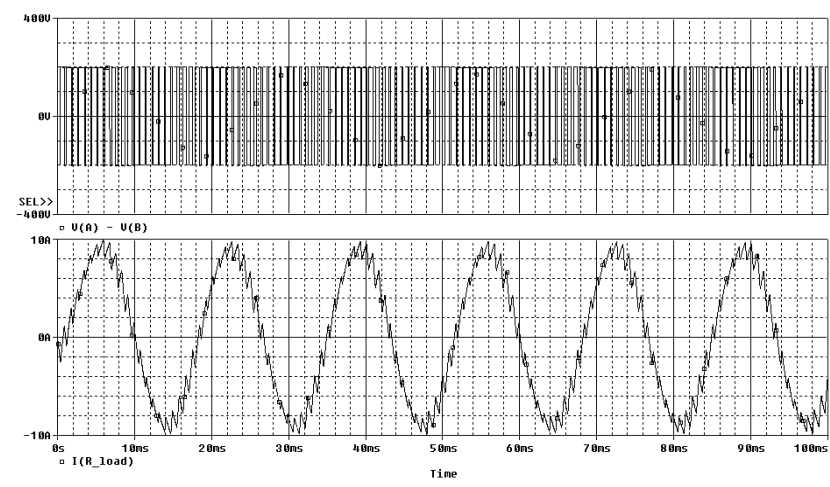

b) Partial simulation results

Figure 5. Full-bridge DC/AC converter with bi-polar switching 


\section{FEEDBACK CONTROL DESIGN OF POWER ELECTRONIC CONVERTERS}

In traditional teaching of power electronics, feedback controls of power electronic converters were not covered. This greatly affected student interests in the course. Students used to think that the course is electric power related and "old-fashioned". This prevented them from seeing how modern power electronics is related to technology advances in the field of electrical and computer engineering. To give students proper view on wide power electronic applications in many high tech related fields, it is important to introduce feedback control design and analysis in the course of Power Electronics.

However, it is not required for students to have the linear control background [16]. To develop student ability in feedback control design and analysis of a power electronic converter, the following approaches have been used: 1) introducing from typical control examples to basic control concepts and block diagrams representation of Figure 6; 2) understanding that the fundamental design objective is to make controlled variable follow the reference input change by designing feedback $\mathrm{H}(\mathrm{s})$ or compensator $\mathrm{D}(\mathrm{s})$ [16]; and 3) designing $\mathrm{H}(\mathrm{s})$ and $\mathrm{D}(\mathrm{s})$ by using the Bode plots which students normally have extensive practices from previous courses such as Electric Circuits [8], Electronics [9], and Circuits and Electronics Lab [7].

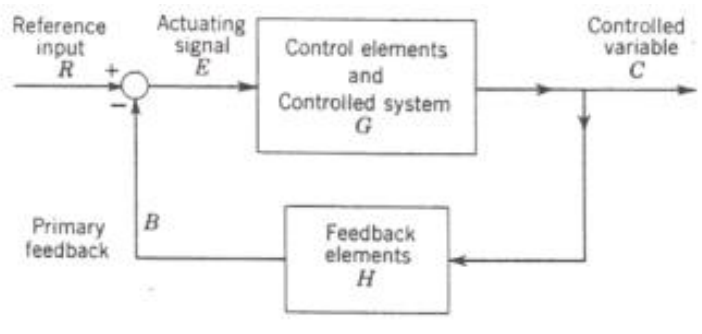

a) A feedback system

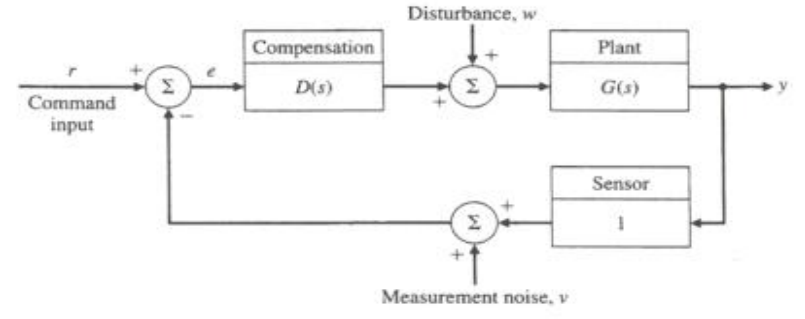

b) A unit feedback system

Figure 6. Block diagrams of feedback control systems

For a normal DC/DC converter control block diagram represented by Figure 6 b), G(s) and $\mathrm{D}(\mathrm{s})$ represent converter and controller transfer functions respectively. The converter Bode plots of G(s) can be easily obtained by using the average model which is represented by an ideal transformer with controllable turn-ratio for a switching element [17]. This average model approach makes it possible for students to design a feedback controller for a DC/DC converter rapidly. The effectiveness of the average model can also be well demonstrated in PSpice simulation such as the Buck converter shown in Figure 7 a). After showing the close equivalence (Figure $7 \mathrm{~b}$ ) between a real DC/DC Buck converter configuration and its corresponding average model representation, students can quickly understand the meaning of the average model, draw Bode plots of the converter in PSpice using the average model, and then design compensator (controller) by using Mathcad (see section IV) to meet design specifications in both gain and phase at gain and/or phase cross-over frequencies.

A combined PSpice simulation of the DC/DC converter, the compensator (controller), and the drive circuit can be carried out after the design in Mathcad so as to give students better vision on how it works when all parts are put together in a "real" circuit as shown in Figure 8 a). For simulation results shown in Figure $8 \mathrm{~b}$ ), there is a source voltage (Vs) change from 20V to $16 \mathrm{~V}$ at $5 \mathrm{~ms}$, a control reference voltage (Vref) change from $10 \mathrm{~V}$ to $8 \mathrm{~V}$ at $10 \mathrm{~ms}$, and a load 
resistance change from $10 \Omega$ to $5 \Omega$ at $15 \mathrm{~ms}$. The simulated results can let students see how the source voltage change, the control reference change, and/or the load resistance change will affect the controlled output voltage Vout, the inductor current $\mathrm{I}(\mathrm{L})$ and the load current I(Rload) from virtual circuit points of views. This virtual circuit oriented simulation will give students deep impression, clear understanding, and strong interests of feedback controls applied to power electronic converters.

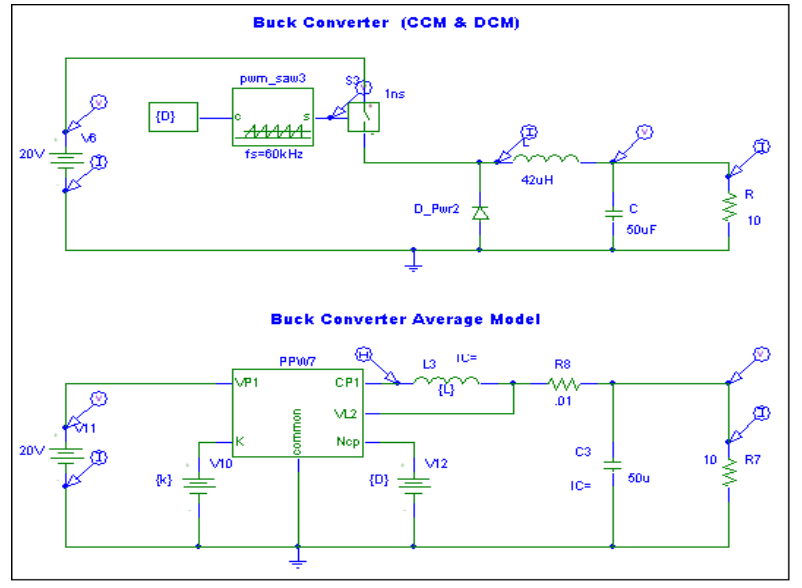

a) Buck converter and its average model

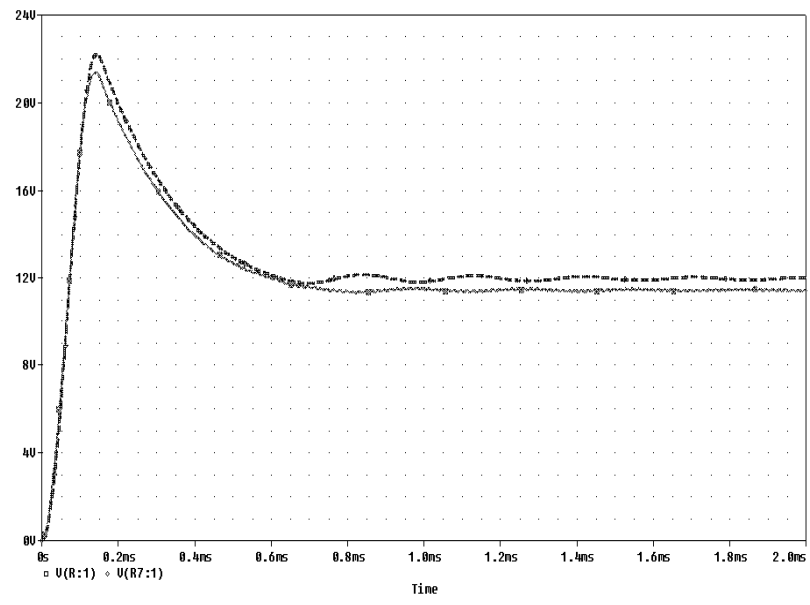

b) Simulated output voltages

Figure 7. Comparison between Buck converter and its average model

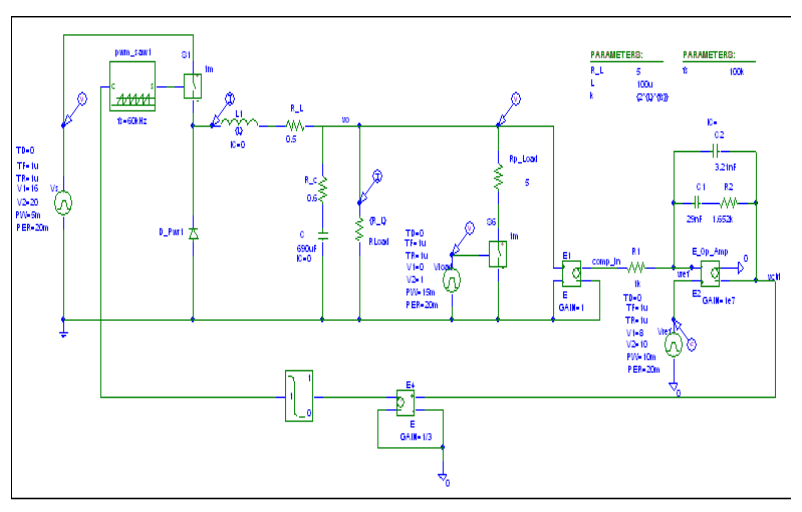

2)

a) The schematic

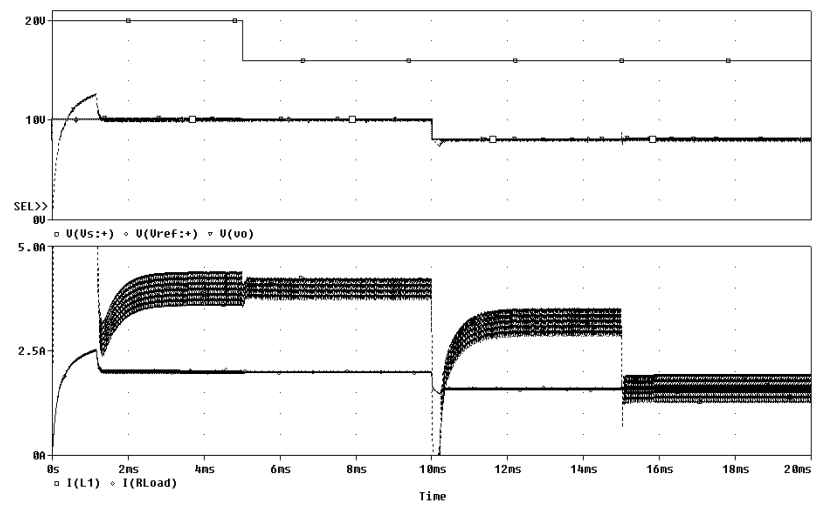

b) Simulation results

Figure 8. Buck DC/DC converter with feedback control

It is important to indicate that the understanding and knowledge in feedback controls that students achieve cannot be replaced by or obtained in other general control related courses such as Linear Control Systems [16]. In other words, students will have more comprehensive apprehension from more circuit oriented points of views on how a control system works when different parts of the system are put together. In addition, the PSpice simulation can let students see how to integrate a power electronic converter, the controller (compensator), and drive circuit together in a "real" circuit and evaluate the performance of controllers and controlled converters in more "practical” ways.

\section{WEB-BASED TEACING MATERIALS}

Proceedings of the 2005 American Society for Engineering Education Annual Conference \& Exposition Copyright (C) 2005, American Society for Engineering Education 
There are many web-based teaching materials for Power Electronics. One of the webbased teaching materials is the Interactive Power Electronics Seminar (iPES) at http://www.ipes.ethz.ch/ipes/index.html. This web-based seminar has been used effectively and conveniently to assist students to understand many basic concepts of various power electronic converters both inside and outside the classroom environment.

Figure 9 demonstrates an example of the online seminar used to teach the fundamental operating principles of a Buck converter. In Figure 9 a), it presents typical waveforms of the input and output voltages, the inductor current, and the switch gate control signal for a Buck converter under $50 \%$ duty cycle. By dragging the vertical (red) time-marker line as well as other changeable factors with the mouse, it is very easy for students to understand the basic behavior of the converter for the switch on (Figure 9 b) and off (Figure 9 c) as well as for the converter under continuous or discontinuous mode (Figure $9 \mathrm{~d}$ ). This strong dynamic effect of the webbased seminar is very effective for students to understand the fundamental operating principles and characteristics of different converters and to provide them with certain preliminary groundwork for more detailed converter analysis and design using other computer IT tools such as Mathcad and PSpice.

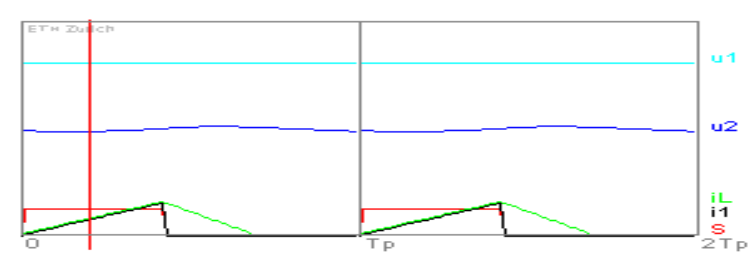

a) Waveforms

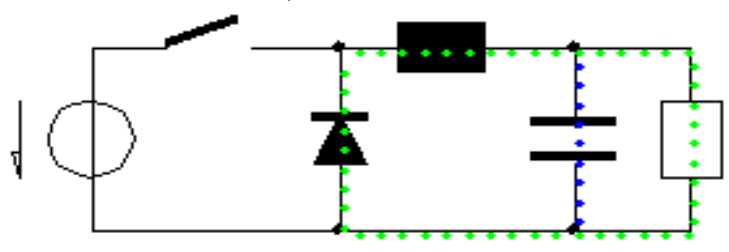

c) Switch off

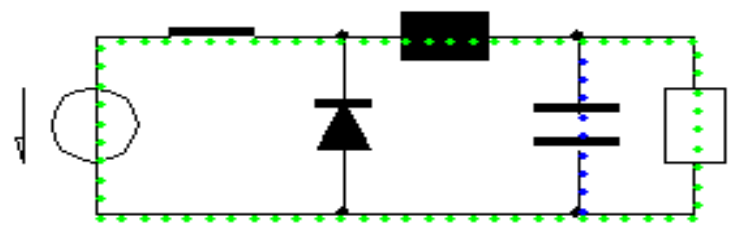

b) Switch on

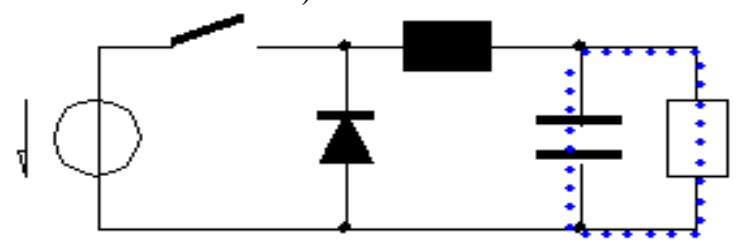

d) Switch off in discontinuous period

Figure 9. Web-based interactive power electronics seminar for Buck converter

\section{LABORATORY DEVELOPMENT}

In the restructured Power Electronics course, a diverse converter topologies are covered in a rapid succession so that it is important to have hardware-based experiments performed concurrently by students to ensure that those concepts are grasped by the students and also to prepare them to the "real world" where they can build, test or use real hardware. The development of the hardware-based laboratory for the course is based upon a power electronic drive board [18] and a power-pole circuit board [19].

The power electronic drive board is actually developed to work as a switch-mode converter for various experiments related to the controls of DC and AC electric drives [20] as shown by Figure 10. However, this drive board configuration is also good for several experiments in Power Electronics such as four-quadrant DC/DC converter, and single and three- 
phase DC/AC inverters. The bi-positional switch of a power-pole [17] in the figure is used to represent the same functionality of a practical electronic switch under the ideal switching condition, making it much easier and faster for students to understand and analyze fundamental characteristics of the switch-mode converters.

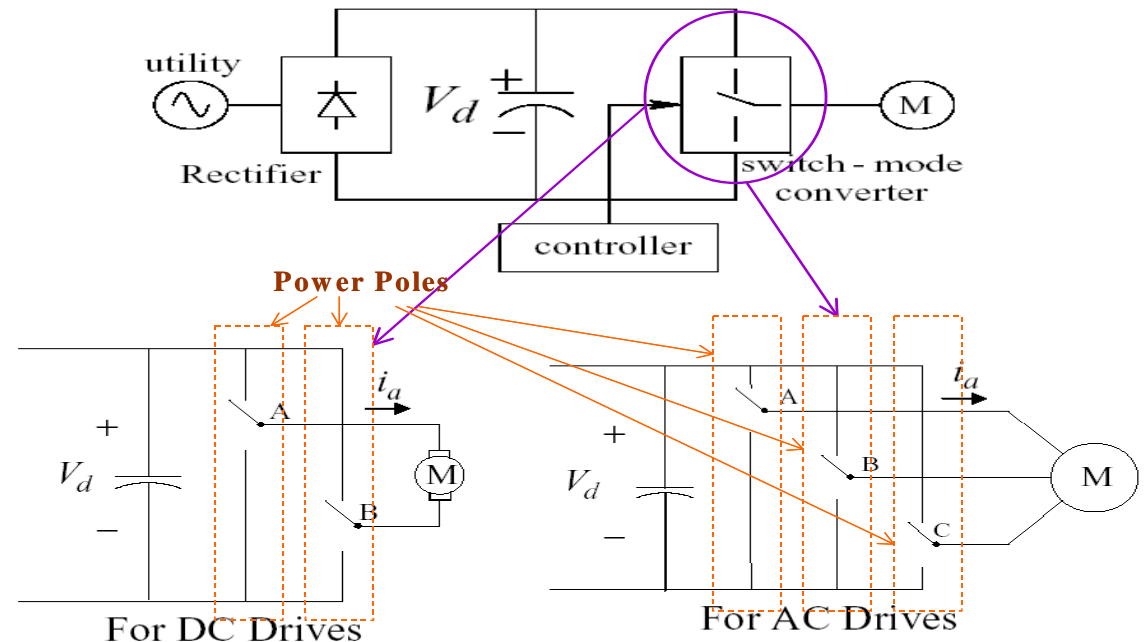

Figure 10. Switch-mode converter and its power-pole representation in electric drive systems

A corresponding hardware implementation of the power electronic drive board is shown in Figure 11 [18]. The drives board has introduced digital control and DSP technologies by using the MATLAB Simulink and dSPACE. It has a $42 \mathrm{~V}$ dc-bus voltage input from a rectified dc power supply, two completely independent 3-phase PWM inverters for complete simultaneous control of two converters, digital PWM input channels for real-time digital control of converters, and complete digital/analog interface with dSPACE board. Each of the three phase converters can be used to implement a four-quadrant DC/DC converter or a single-phase DC/AC inverter when only two of the three power-poles are used or a three-phase DC/AC inverter when all the three poles are used.

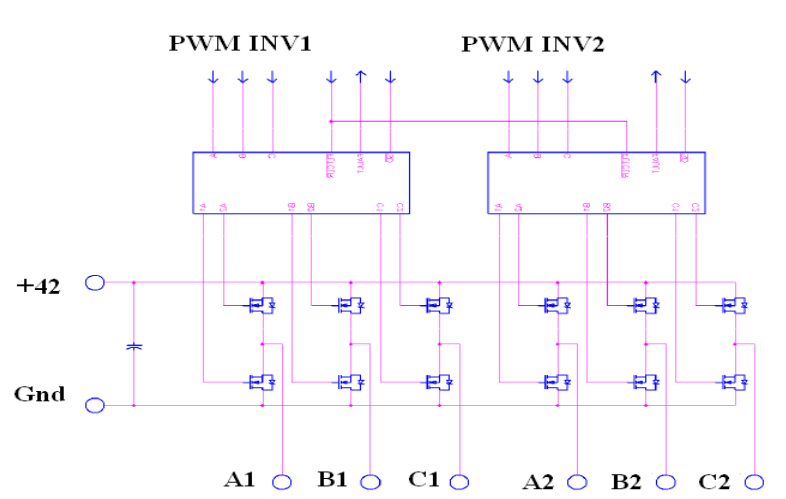

a) Block Diagram

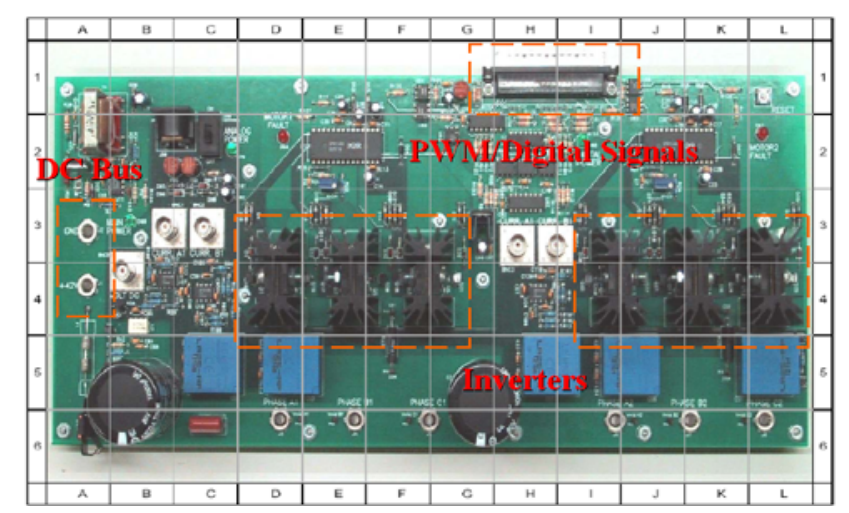

b) Hardware Implementation

Figure 11. Power electronic converters for DC and AC machine drives

The basic block diagram of the power-pole circuit board is shown in Figure 12 a) and the actual board configuration is shown in Figure $12 \mathrm{~b}$ ). The main feature of the board is the reconfigurable power-pole consisting of two MOSFETs and two diodes. The drive circuits for 
the MOSFETs are incorporated on the board. PWM signals to control the MOSFETs can be generated onboard or supplied from an external source. The power-pole can be configured to work in various topologies using three magnetics boards (BB board for buck, boost and buckboost converters, Flyback board for flyback converter, and Forward board for forward converter) which plug into the power-pole circuit board. In addition, there is an option of doing frequency analysis of each topology by injecting a small-signal sinusoidal control voltage. The board can also be operated in voltage/current feedback mode using an external control circuit mounted on a daughter board which plugs into the power-pole circuit board [18].

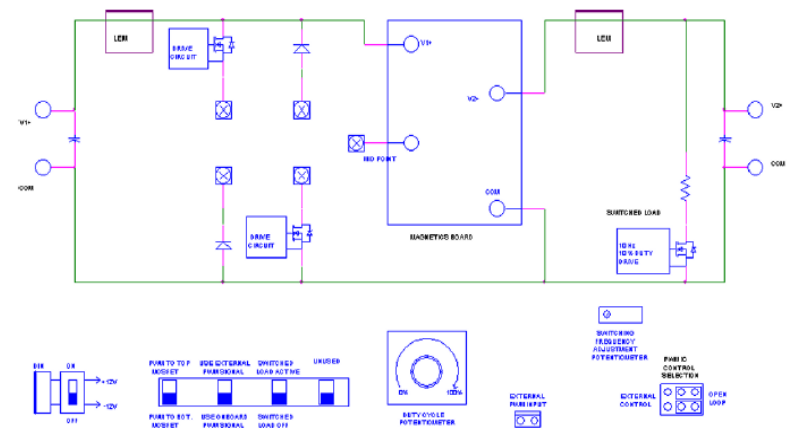

a) Block diagram

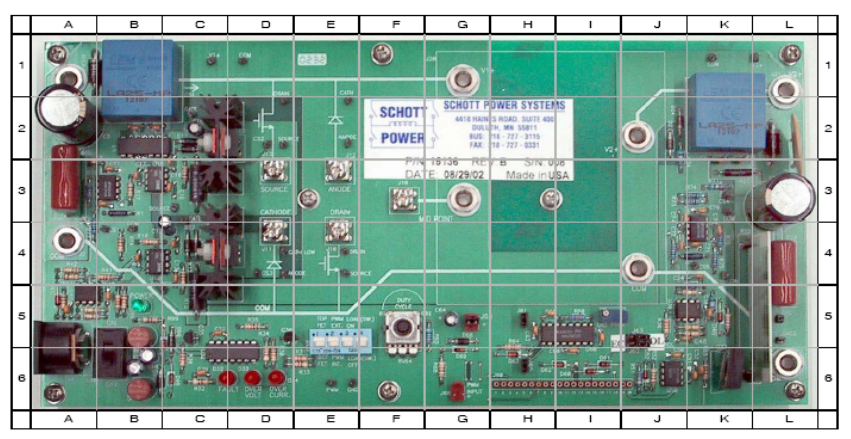

b) The board

Figure 12. Power-pole board

The power-pole circuit board enables laboratory experiments for measurement of several DC/DC power electronic converters as well as associated feedback controls. These include experiments of Buck, Boost, Buck/Boost, Forward, and Flyback DC/DC converters and experiments of the feedback control design and measurement of DC/DC converters. For many experiments, a short animated PowerPoint presentation as illustrated in Figure $11 \mathrm{~b}$ ) has been developed to show basic concepts and operations of an experiment before starting it. This is effective and efficient to result in more productive and quality results obtained by students from an experiment.

Significant computer data acquisition techniques have been used and introduced for all experiments developed using both the power-pole circuit board (Figure 12) and the power electronic drive board (Figure 11). These include: 1) getting measured data or waveforms from the TDS2014 oscilloscope to a digital computer by using the OpenChoice software and 2) getting data through a completely computer data acquisition system by using the dSPACE control desk layout and corresponding hardware DS1104 [12]. Those computer data acquisition systems have greatly improved the ways of teaching and learning. Rather than focusing on tedious and/or time consuming methods of gathering data, students can obtain measured results much faster and more efficiently. Results can be obtained by capturing the screen and/or by saving to data files for future analysis in Microsoft Excel. This not only makes it possible to have much more lab contents in an experiment but also makes students more focused on results, concepts, relations to theories, and/or design aspects of the experiment, providing an improved and favorable methodology for quality education.

For most experiments, the spreadsheet tables have been used for data recording, certain automatic theoretical calculations, and result analysis [21]. This has saved the time of an 
experiment a lot and made students more focused on other aspects of measurement and analysis. It is worth to point out that the result analysis by using many features of Microsoft Excel could give students better visions on the corresponding experimentation objectives than using a prewritten program such as a MATLAB program. This could result in higher quality educational goals from the hands-on experimentation.

Several experiments require students to perform and compare computer simulation and actual hardware measurement. Figure 13 shows an experiment of simulation and real-time implementation for that purpose for an example of a two-pole switch-mode converter. The average model of a power-pole [8], represented by an ideal transformer with controllable turnratio, makes it possible for students to quickly develop Simulink duty-ratio generation models in a laboratory environment to control power electronic converters in both simulation and real-time implementation. In the simulation model of Figure 13 a), the duty-ratio calculator can be easily obtained based upon the average model concepts, and the converter model can be simply acquired based upon the power-pole model concepts. Then, the same duty-ratio calculator model is used in Figure $13 \mathrm{~b}$ ) for the real-time open-loop control of the actual switch-model converter (Figure 3). Through such an experiment, students can more clearly understand the theoretical concepts of the power-pole and the average models and apply them to implement a real-time DSP system to control the switch-mode converters for different output voltage needs as illustrated in Figure $13 \mathrm{c}$ ) and d) for both simulated and measured results. The application of the modern computer IT tools, such as the one shown by Figure 13, has not only helped them to understand theories more effectively through hands-on experimentation but also given them opportunities to learn modern computer software and hardware.

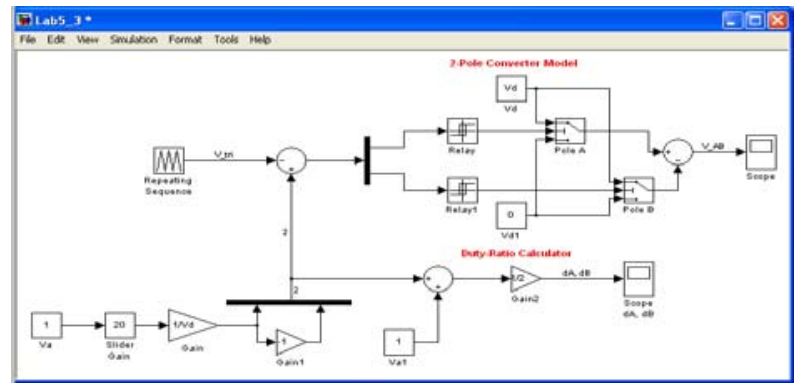

a)

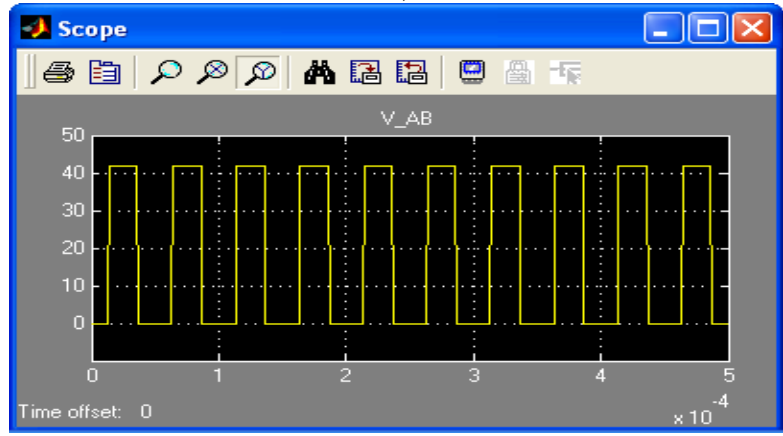

c)

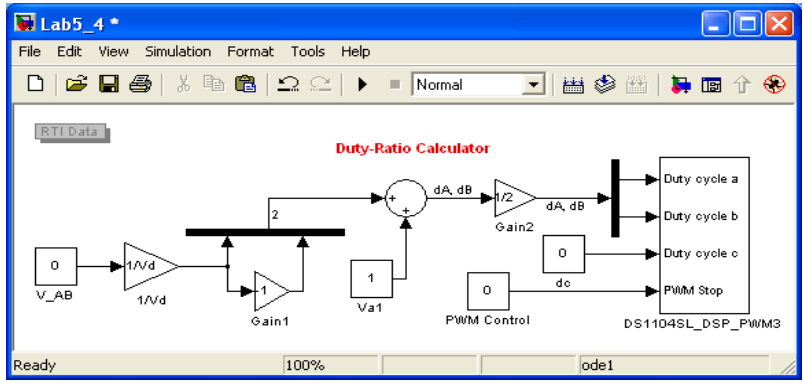

b)

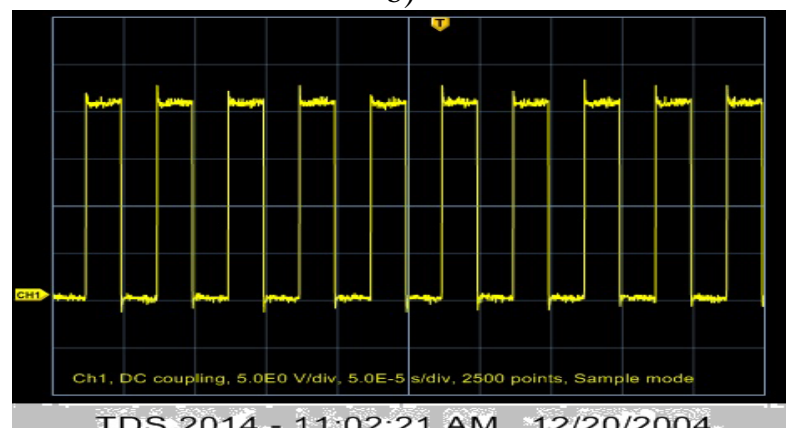

TDS 2014-11:02:21 AM 12/20/2004

d)

Figure 13. Simulation and real-time implementation of open-loop switch-mode converter control

\section{Conclusions}


This paper presents the application of information technology (IT) tools in teaching the course of Power Electronics at Texas A\&M University - Kingsville. It presents the usage of the power-pole and average models in the teaching so as to be able to teach broad power electronic converter topologies. It also shows the development of a new power electronics laboratory by using various IT tools.

The paper gives our teaching practice to build up strong virtual measurement concepts of simulation to students through significant comparison between simulation in PSpice and computer hardware measurement in LabView. It then shows how PSpice is used as a virtual hardware laboratory tool to teach students various converter topologies and feedback control design and analysis. Mathcad is used as another powerful IT tool for teaching the course on the theoretical background and design issues related power electronic converters and feedback controls. The paper illustrates the application of the web-based course materials to assist students understanding of the operating principles of various power electronic converters.

The paper presents laboratory development by using several other IT tools. The paper shows PSpice, Mathcad, OpenChoice, MATLAB Simulink, dSPACE ControlDesk and Microsoft Excel software and/or hardware used in the laboratory for simulation, analysis, control, measurement, data acquisition, and result analysis in the newly developed power electronics laboratory.

\section{References}

[1] Paul W. Tuinenga, SPICE - A Guide to Circuit Simulation \& Analysis Using PSpice, Upper Saddle River, NJ: Prentice Hall, 1995.

[2] Muhammad H. Rashid, Introduction to PSpice Using OrCAD for Circuits and Electronics, Upper Saddle River, NJ: Prentice Hall, $3^{\text {rd }}$ ed., 2004.

[3] John P. Borris, Electric Circuits Using Electronics Workbench: Hardware and Simulation Exercises, Upper Saddle River, NJ: Prentice Hall, $2^{\text {nd }}$ ed., 2000.

[4] Campbell, J. O., Bourne, J., Mosterman, P., and Brodersen. A. J., "The Effectiveness of Learning Simulations for Electronic Laboratories,” Journal of Engineering Education, Vol. 91, No. 2, 2001.

[5] Hmurcik, L. V., Hettinger, M., Gottschalck, K. S., and Fitchen, F. C., "SPICE applications to an undergraduate electronic program," IEEE Transactions on Education, Vol. 33, pp. 183-189, 1990.

[6] Abuelma'atti, M.T. and Qamber, I.S., “Applications of SPICE simulation software to the study of reliability and availability in electrical engineering education," IEEE Transactions on Education, Vol. 45, No. 3, pp. 209- 217, Aug. 2002.

[7] Shuhui Li and Abrar A. Khan, "Developing Digital Measurement and Analysis Laboratory in Circuits and Electronics Lab at TAMUK,” in the Proceedings of 2004 ASEE Annual Conference, Salt Lake City, USA, June 20 - 23, 2004.

[8] A. B. Carlson, Circuits, Brooks/Cole, 2000.

[9] Allan R. Hambley, "Electronics,” Prentice Hall, 1999.

[10] D. W. Hart, Introduction to Power Electronics, Upper Saddle River, NJ: Prentice Hall, $2^{\text {nd }}$ ed., 1997. 
[11] Mathsoft Engineering \& Education, Inc., Mathcad 11 User Guide, Cambridge, MA: Mathsoft Engineering \& Education, Inc., 2002.

[12] DeLyser, R. R., "Using Mathcad in electromagnetics education," IEEE Transactions on Education, Vol. 39, No. 2, pp. 198-210, May 1996.

[13] Whites, K. W., "Visual electromagnetics for Mathcad: A computer-assisted learning tool for undergraduate electromagnetics education," in Proc. 1998 IEEE Antennas and Propagation Society Int. Symp., Vol. 4, pp. 2288-2291, 1998.

[14] Ramirez, J. M. and Baez-Lopez, D., "An experimental simulation lab in MathCAD for teaching signal processing," in Proc. 6th IEEE Digital Signal Processing Workshop, pp. 123-126, 1994.

[15] Veglis, A.A., Barbargires, C.A., and Pombortsis, A.S., "Teaching performance evaluation of multiprocessor architectures with Mathcad and MathConnex," IEEE Transactions on Education, Vol. 54, No. 3, pp. 231- 237, 2002.

[16] John J. D'Azzo and Constantine H. Houpis, "Linear Control System Analysis and Design,” McGraw-Hill, Inc., 1995.

[17] N. Mohan, "Power Electronics and Drives," ISBN 0-9715292-2-1, Minnesota Power Electronics Research \& Education, 2003.

[18] “DSP Based Electric Drives Laboratory User Manual," Department of Electrical and Computer Engineering, University of Minnesota, 2003.

[19] "Power Electronics Laboratory User Manual," Department of Electrical and Computer Engineering, University of Minnesota, 2003.

[20] Shuhui Li and Rajab Challoo, "Restructuring Energy Conversion Course Using An Integrative Approach and Computer Assisted Teaching Approaches," in the Proceedings of 2004 ASEE Annual Conference, Salt Lake City, USA, June 20 - 23, 2004.

[21] “Microsoft Excel User’s Guide," Microsoft Corporation, Redmond, WA, Version 9.0, 1999.

SHUHUI LI received his B.S. and M.S. degrees in Electrical Engineering from Southwest Jiaotong University in Chengdu, China in 1983 and 1988 respectively and Ph.D. degree in Electrical Engineering in 1999 from Texas Tech University. From 1988 to 1995, he was with the School of Electrical Engineering at Southwest Jiaotong University, where his research interests were in the areas of modeling and simulation of large dynamic systems, dynamic process simulation of electrified railways, power electronics, power systems, and power system harmonics. From 1995 to 1999, he involved into the research areas of renewable energies, neural networks, and applications of massively parallel processing. He joined the Department of Electrical Engineering and Computer Science at Texas A\&M University - Kingsville (TAMUK) in 1999. He is currently an associate professor at TAMUK. He is a member of IEEE and ASEE.

RAJAB CHALLOO is a professor in the EE/CS department. He has been teaching and conducting research at Texas A\&M University - Kingsville since 1988. In the department of electrical engineering, he has served as acting chairman, graduate coordinator, chairman of the curriculum committee, scholarship committee and research committee. At the college level, he has severed as the chairman of the graduate council, chairman of the executive committee of the graduate council, as a senator representing college of engineering, and a number of many committees. He has been honored by the students in EE/CS department to be the recipient of the professor of the year award four consecutive times and a merit of excellence award. He was named as an honoree for the 1993 University Alumni Association's Distinguished Teaching Award. He has published over forty research papers and has severed as organizer, chairman, and reviewer for many national and international conferences. 